This is the peer reviewed version of the following article: Harder R, Heimersson S, Svanström M, Peters GM (2014) Including pathogen risk in life cycle assessment of wastewater management. 1. Estimating the burden of disease associated with pathogens, Environmental Science and Technology 48(16):9438-9445, which has been published in final form at http://dx.doi.org/10.1021/es501480q.

\title{
Including pathogen risk in life cycle assessment of wastewater management. 1. Estimating the burden of disease associated with pathogens
}

\author{
Robin Harder ${ }^{\mathrm{a}}$, Sara Heimersson ${ }^{\mathrm{a}}$, Magdalena Svanström ${ }^{\mathrm{a}}$, Gregory M. Peters ${ }^{\mathrm{a}}$ \\ ${ }^{a}$ Department of Civil and Environmental Engineering, Chalmers University of Technology, \\ Gothenburg, Sweden
}

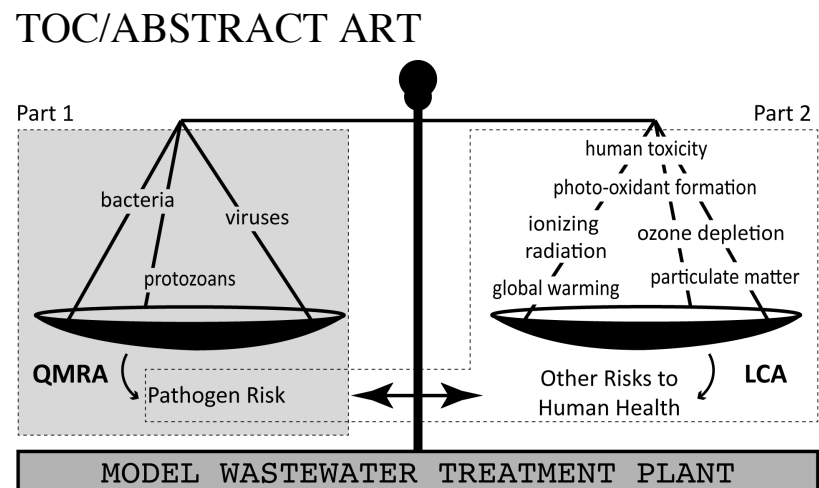

ABSTRACT: The environmental performance of wastewater and sewage sludge management is commonly assessed using life cycle assessment (LCA), whereas pathogen risk is evaluated with quantitative microbial risk assessment (QMRA). This study explored the application of QMRA methodology with intent to include pathogen risk in LCA and facilitate a comparison with other potential impacts on human health considered in LCA. Pathogen risk was estimated for a model wastewater treatment system (WWTS) located in an industrialized country and consisting of primary, secondary and tertiary wastewater treatment, anaerobic sludge digestion, and land application of sewage sludge. The estimation was based on eight previous QMRA studies as well as parameter values taken from the literature. A total pathogen risk (expressed as burden of disease) in the order of $0.2-9$ disability-adjusted life years (DALY) per year of operation was estimated for the model WWTS serving 28,600 persons, and for the pathogens and exposure pathways included in this study. The comparison of pathogen risk with other potential impacts on human health considered in LCA is detailed in part 2 of this article series.

KEYWORDS: microbial risks, LCA, QMRA, hybridization, wastewater, sewage sludge, biosolids

\section{ADDRESS CORRESPONDENCE TO}

Robin Harder: robin.harder@wetryharder.ch 


\section{INTRODUCTION}

In light of the ongoing debate on the finite nature of phosphorus resources and potential future phosphorus scarcity ${ }^{1-3}$, land application of sewage sludge is promoted as one possible way of recycling nutrients and organic material to productive land, and by this means closing nutrient and carbon cycles. However, concerns are raised regarding the risks that land application of sewage sludge poses to human health and the environment. ${ }^{4-7}$ Of particular concern are inorganic pollutants (e.g., heavy metals), organic pollutants (e.g., industrial chemicals, pharmaceutical residues and hormones), and pathogens (e.g., bacteria, viruses and parasites).

Pathogen risk related to wastewater and sewage sludge management results from the exposure of humans to different pathogens through various exposure pathways. Note that strictly speaking, pathogen risk also results from the exposure of animals to different pathogens (e.g. foot-and-mouth disease, mad cow disease, and African swine fever). However, animals were not included as receptors of pathogens in this study. In any case, pathogen risk is commonly estimated through quantitative microbial risk assessment (QMRA). Chemical risk results in a similar way from the exposure of any kind of organism to different chemicals through various exposure pathways. This risk is commonly estimated through human health risk assessment for the exposure of humans, and ecological risk assessment for the exposure of ecosystems.

In recent times, considerable efforts have been made towards improving sludge quality by developing novel routes and technologies for wastewater and sewage sludge management. ${ }^{8}$ The environmental performance of different management options is commonly evaluated using life cycle assessment (LCA). For a comprehensive review of LCA of wastewater management the reader is referred to Yoshida and colleagues ${ }^{9}$ and Corominas and colleagues ${ }^{10}$. In LCA, Life Cycle Impact Assessment (LCIA) methodology translates resource use and emissions that occur in the life cycle of a product or service into potential impacts on the environment (including human health). Whilst LCIA methodology is under development for toxic effects of chemicals on human health (i.e. human toxicity) and ecosystems (i.e. ecotoxicity), the effects of pathogens are not currently considered in LCA.

Many earlier QMRA studies assessing pathogen risk related to municipal wastewater and sewage sludge management ${ }^{6,11-19}$ calculated the probability of infection (or illness) per individual and event, or per individual and year, or the number of cases of infection (or illness) for each combination of pathogen and exposure pathway included in the respective study. These earlier studies did not address how the risks resulting from various pathogens and exposure pathways can be aggregated to a cumulative pathogen risk, and how this pathogen risk compares with other potential impacts on human health. The possibility of assessing the cumulative risk resulting from the exposure of humans to several pathogens through several exposure pathways would facilitate a meaningful comparison of the potential impact of pathogens on human health with other potential impacts on human health considered in LCA. Such assessment requires some kind of weighting or severity factor for each pathogen considered.

Disability-adjusted life years (DALY) is a concept developed by the World Health Organisation $^{20}$ and includes both the years of life lost (YLL) and the years lived with disability (YLD) as a result of a given health problem. Both in LCIA and QMRA, expressing 
the burden of disease (related to pathogen or chemical risks) in DALY has been adopted as a way of weighting different potential impacts on human health. The burden of disease (in DALY) has for instance been calculated in several previous QMRA studies assessing pathogen risk related to recycled water schemes ${ }^{21-27}$, which suggests that a similar approach would be possible also in the context of municipal wastewater and sewage sludge management. The adoption of the DALY concept in both QMRA and LCIA furthermore suggests that it may be possible to integrate QMRA results in a LCA framework. Indeed, Aramaki and colleagues ${ }^{28}$ contrasted the reduction of pathogen risk (on a local level) associated with the installation of an urban wastewater system with increased health risks (on a global level) resulting from construction and operation of the treatment plant; the respective study covered three pathogens and one exposure pathway (downstream water abstraction for drinking water production).

The higher-level goal of this study was to explore the inclusion of pathogen risk in LCA with intent to compare the potential impacts of pathogens on human health with other potential impacts on human health commonly accounted for in LCA. More specifically, this study aimed at exploring the integration of QMRA in a LCA framework in the context of municipal wastewater and sewage sludge management. Whilst the approach followed in this study is similar to the approach of Aramaki and colleagues ${ }^{28}$, the present study is much more comprehensive in the coverage of pathogens and exposure pathways. This article is part 1 of an article series and reports on the estimation of cumulative pathogen risk associated with a model wastewater treatment system (WWTS) situated in an industrialized country. The comparison of pathogen risk with other potential impacts on human health considered in LCA is detailed in part 2 of this article series ${ }^{29}$.

\section{METHODS}

This study was based on eight previous QMRA studies ${ }^{11-14,16-19}$ on pathogen risk related to municipal wastewater and sewage sludge management. More details on these studies are provided in the Supporting Information (e.g., focus of the respective study, pathogens and exposure pathways covered, assessment endpoints applied). These studies formed the basis for estimating the overall pathogen-related burden of disease associated with a model WWTS. The model WWTS used in this study for the estimation of pathogen risk is based on the WWTS described by Westrell and colleagues ${ }^{19}$. This WWTS with 28,600 persons connected treats $12,500 \mathrm{~m}^{3}$ wastewater per day on average and consists of primary and secondary treatment (activated sludge process with biological nitrification-denitrification and chemical phosphorus removal), tertiary treatment (constructed wetland), anaerobic sludge digestion, and land application of sewage sludge. The study by Westrell and colleagues ${ }^{19}$ was chosen because it provided the most comprehensive set of exposure pathways including parameter values for exposure dose, exposure frequency, and number of persons affected. The set of exposure pathways considered by Westrell and colleagues ${ }^{19}$ was complemented with exposure pathways reported in four other studies ${ }^{14,16-18}$ in order to increase the coverage of pathogens and exposure pathways.

Since not all studies reported results for all combinations of exposure pathway and pathogen, and not all studies reported the underlying models and parameter values, two 
estimation approaches were applied. First, risk estimates for different pathogens and exposure pathways reported in various previous QMRA studies were converted into burdens of disease (literature-based approach). Second, a QMRA model was built based on transport, fate, and exposure models described in previous QMRA studies (model-based approach). The results obtained through the two approaches were then combined in order to maximize the number of different combinations of pathogen and exposure pathway included in the estimation of the overall pathogen risk (expressed as burden of disease).

\subsection{Estimating the overall burden of disease based on previous QMRA studies}

The literature-based approach started from the probabilities of infection (or illness) per individual and event or per individual and year, or the number of cases of infection (or illness) reported in five previous QMRA studies ${ }^{14,16-19}$. The exposure pathways covered in the literature-based approach are indicated in Table 1. The results reported in previous QMRA studies were converted to burdens of disease (in DALY) using the assumptions on exposure frequencies and individuals exposed reported by Westrell and colleagues ${ }^{19}$ (Table 1) and severity factors (i.e. burden of disease per case of infection or illness) taken from the literature $^{30-32}$ (for parameter values see Supporting Information).

\subsection{Estimating the overall burden of disease based on a QMRA model}

The model-based approach consisted of building a QMRA model starting from pathogen concentrations in raw wastewater, effluent, raw sewage sludge, and treated sewage sludge.

\subsubsection{Hazard identification}

The pathogens included in the QMRA model are those of common concern in wastewater and sewage sludge management. Bacteria considered are: Campylobacter, Salmonella, Listeria, and pathogenic Escherichia coli (usually strain O157:H7). Viruses considered are: Enterovirus (usually represented by Coxsackievirus), Rotavirus, Adenovirus, and Norovirus. Protozoans considered are Giardia and Cryptosporidum. Helminths play a minor role in industrialized countries. ${ }^{33}$ The pathogens considered in this study are summarized in Table 2 . Common receptors in QMRA studies assessing wastewater and sewage sludge management are adults and children, who are exposed to pathogens through accidental, intentional, or routine ingestion, inhalation, or dermal contact during occupational, recreational, or residential activities.

\subsubsection{Exposure assessment}

In QMRA, pathogens are tracked from the source through different compartments to specific receptors, thereby taking into account specific transport and exposure conditions. Transport and fate models describe how pathogens move from one compartment to another, whilst exposure models describe how pathogens move from compartments to receptors. In this study, the starting point for exposure assessment was raw wastewater, treated effluent, raw sewage sludge, and treated sewage sludge, respectively. An overview of the pathogen concentrations found in the literature ${ }^{35-53}$ for the respective compartments is provided in the Supporting Information. The transport pathways of pathogens between different environmental compartments as well as the exposure pathways from environmental compartments to receptors are visualized in Figure 1. 
The most common type of transport and fate model are compartment models, which assume well-mixed homogeneous environmental compartments (i.e. pathogen concentrations are a function of time only). For the dispersion of aerosols in air, however, plume models are often applied that take into account that the distribution across the compartment is nonuniform (i.e. pathogen concentrations are a function of time and space). The compartment models used in this study were based on Brooks and colleagues ${ }^{14}$. The aerosol dispersion model was based on an empirical formula derived by Brooks and colleagues ${ }^{11,12,14}$. The calculation models for pathogen exposure through a given exposure pathway were also based on Brooks and colleagues ${ }^{14}$. More details on the transport, fate, and exposure models are provided in the Supporting Information.

\subsubsection{Dose-response assessment}

Dose-response models translate a pathogen dose into a probability of infection or illness. Pathogen dose per day as calculated during exposure assessment was converted into probabilities of infection or illness per day using dose-response relationships in the form of an exponential model or a beta-Poisson model. The parameter values used for dose-response assessment were taken from the literature ${ }^{54-62}$. More details on the dose-response models and the parameter values are provided in the Supporting Information.

\subsubsection{Severity assessment}

Probabilities of infection or illness per day were converted into burden of disease using severity factors (i.e. DALY per case of infection or illness) taken from the literature ${ }^{30-32}$. More details on the severity assessment and the parameter values are provided in the Supporting Information.

\subsection{Triangulation of burden of disease estimates}

The exposure pathways considered in the literature-based and the model-based approach are listed in Table 1 along with data from the literature on exposure frequency and individuals exposed. Note that not all combinations of pathogens and exposure pathways covered by the literature-based approach were covered by the model-based approach and vice versa. Figure 2 gives an overview of the coverage of the two respective approaches as well as the overlap between them. In order to obtain a burden of disease estimate that covers as many combinations of pathogen and exposure pathway as possible, the estimates obtained through the two approaches were combined, which allowed for a validation of results between the approaches for combinations of pathogens and exposure pathways covered by both. This concurrent validation and combination of methods will here be referred to as a triangulation.

A lower and an upper boundary for the burden of disease associated with each combination of pathogen and exposure pathway was calculated based on the literature-based approach (i.e. five previous QMRA studies) and the model-based approach (i.e. QMRA model used in this study). The lower and upper boundaries were calculated as the geometric mean of the lower and the upper boundaries, respectively, of all (literature-based and model-based) burden of disease estimates featuring a specific combination of pathogen and exposure pathway. 


\subsection{Model implementation}

The QMRA model was built both in MATLAB R2013a and in Microsoft Excel 2011 for reasons of model validation. The MATLAB version of the model was run as Monte Carlo simulations with 10,000 iterations. Pathogen concentrations were modeled so that the natural logarithm of the pathogen concentration followed a triangular distribution. All other parameter values were sampled from uniform distributions with upper and lower boundaries equivalent to the ranges provided in this article. The Excel version of the model did not support Monte Carlo simulation.

\section{RESULTS}

The literature-based and the model-based burden of disease estimates for distinct combinations of pathogen and exposure pathway were in good agreement with each other (i.e. overlapping ranges) for many of the combinations covered by both approaches (Figure 3). Similarly, within the literature-based approach, there was good agreement between the results of different previous QMRA studies. However, for Salmonella (P05) and Giardia (P10) the model-based approach estimated a higher burden of disease than the literature-based approach for every single exposure pathway.

Based on the combination of both approaches, the total pathogen-related burden of disease for the model WWTS considered in this study was estimated to be in the order of $0.2-9$ DALY per year of operation for the population served (28,600 individuals), and for the combinations of exposure pathway and pathogen included in this study. Note that no severity factor expressing the burden of disease of an infection with Enterovirus could be found in the literature. As a result, Enterovirus is not included in the overall pathogen risk (expressed as burden of disease) reported in this study. If a severity factor of 0.0055 DALY per incidence (average of the respective parameter value for Norovirus, Adenovirus and Rotavirus) were used, the respective pathogen-related burden of disease would be in the order of $0.2-11$ DALY per year. In comparison, a one in a million risk of a lethal accident of an average individual (aged 40 with a life expectancy of 80 years) in the population served by the model WWTS would amount to 1.1 DALY. The pathogen-related burden of disease estimates obtained from the literature-based and the model-based approach individually are provided in Table 3. More information on distinct combinations of exposure pathway and pathogen can be found in the Supporting Information.

\section{DISCUSSION}

This study estimated pathogen risk (expressed as burden of disease) associated with a model WWTS with intent to subsequently include the results in LCA. Following a number of sources of uncertainty and bias are discussed and an outlook for LCA practitioners is provided.

\subsection{Sources of uncertainty and bias}

\subsubsection{Selection of model treatment plant, pathogens, and exposure pathways}

This study is based on a specific model WWTS and a limited, non-exhaustive number of exposure pathways. Particularly, the model WWTS represents a scenario that features 
agricultural use of sewage sludge (i.e. land application) but does not consider agricultural use of wastewater effluent (i.e. wastewater irrigation). For a different WWTS configuration, some of the exposure pathways considered in this study may not be relevant whilst others may be missing (particularly in the case of water reclamation).

This study covered ten pathogens; however, depending on the context, additional pathogens may be of relevance. Furthermore, a given pathogen group consists of a great variety of pathogens which may behave differently. The calculation based on ten model organisms representing one pathogen group each is thus a simplification and introduces uncertainty. Nevertheless, the set of pathogens and exposure pathways considered in this study is deemed adequate to provide a rough estimate of the order of magnitude of the overall burden of disease associated with pathogens in wastewater and sewage sludge management in industrialized countries for the wastewater and sewage sludge management scenario chosen in this study (i.e. land application of sewage sludge, no water reclamation). In any case, the combination of literature-based and model-based estimates gives a more comprehensive picture than any single previous study (Table 3 ).

\subsubsection{Pathogen concentrations}

Data on pathogen concentrations in raw sewage, effluent and sewage sludge are highly dependent on the prevalence of pathogens in a catchment, on the characteristics of transport and treatment processes, and on the configuration of the urban drainage system, the WWTP, and sludge handling. The pathogen concentrations used in this study consist of values taken from the literature and thus represent values sampled at different WWTPs in different countries in Europe and North America over a time interval of two decades. It is impossible to determine how representative these values are for the model WWTS underlying this study and there are three main sources of uncertainty and ambiguity. First, there are differences in how pathogens are counted and pathogen concentrations reported in the literature are hence reported in a number of different units. Common units are colony forming units (CFU), most probable numbers (MPN), plaque forming units (PFU), cytopathogenic units, or genome copies. This ambiguity also applies to dose-response models and parameters, which rarely specify explicitly which type of pathogen count they require as input data. Second, there are differences in the reference quantity of the carrier. Common reference quantities are liter, gram wet sludge, gram dry sludge, and gram dry solids. Third, it is sometimes unclear what for instance the term 'raw sludge' exactly refers to as it can be interpreted as either liquid sludge directly after primary or secondary settling, or as thickened sludge before further treatment such as anaerobic digestion. Ambiguity regarding wet and dry sludge can introduce an error of up to one order of magnitude in pathogen doses used as input to dose-response models. Ambiguity regarding pathogen counts can introduce an error of up to four orders of magnitude ${ }^{34}$ in pathogen doses used as input to dose-response models. It is difficult, however, to estimate the uncertainty on the level of burden of disease estimates due to the non-linearity of the dose-response and severity assessment models.

\subsubsection{Combined action of multiple pathogens and distinction of different receptors}

The summation of burdens of disease associated with different specific types of pathogens implies the assumption that different types of pathogens act independently from each other. 
Such independence is also often assumed for toxicity effects of chemicals. However, the effects of mixture toxicity are increasingly being discussed and investigated. ${ }^{63,64}$ In the case of pathogens, taking into account concurrent action of two or more pathogen types would require corresponding dose-response curves, which currently are not available. Hence the modeler in any case needs to resort to the assumption that different types of pathogens act independently from one another in the host. Similarly, it was not possible to distinguish between different receptors (i.e. adults and children); as severity factors describing the health impact of a specific pathogen type were not available for children, the respective severity factors for adults were used.

\subsubsection{Severity factors}

The aggregation of impacts resulting from exposure to different types of pathogens was achieved through weighting the contributions from different pathogens using severity factors expressing the burden of disease per case of infection (or illness) in DALYs. These severity factors are population-specific, that is, they are calculated for a specific country and population group. Furthermore, severity factors may include value-laden aspects such as age weighting and future discounting. ${ }^{31}$ Using severity factors from one country or population group to represent a different population group or a similar population group in a different country introduces uncertainty as a different set of severity factors might be needed. Most severity factors used in this study were calculated for the Netherlands, but are here assumed to be representative for Europe and Northern America. Finally, the weighting of potential impacts of different pathogens inherent in the DALY concept means that a comparison of pathogen risk and other potential impacts on human health considered in LCA will take place at the level of endpoint indicators (see part 2 of this article series ${ }^{29}$ for a more detailed discussion on the implications of this).

\subsection{Outlook for LCA practitioners}

This study was based on the idea of including pathogen risk in LCA through a hybrid assessment approach where the potential impact of pathogens on human health, for which currently no LCIA methodology exists, was quantified using QMRA. The approach taken in this study is similar to two earlier attempts towards inclusion of pathogen risk in $\mathrm{LCA}^{28,65}$ but covered substantially more pathogens and exposure pathways. Pathogen risk was expressed as burden of disease and estimated for a model WWTS based on QMRA models and QMRA results reported in the literature. Among the main challenges faced were lack of data as well as ambiguity and a lack of transparency in many previously reported QMRA studies. In many cases it was difficult, if not impossible, to reproduce the results reported in the respective studies. Despite the sources of uncertainty and bias discussed in this article, the combination of a literature-based and a model-based approach is expected to provide a fairly robust estimate of the overall burden of disease associated with pathogens in the order of $0.2-9$ DALY per year for the model WWTS serving 28,600 persons, and for the combinations of exposure pathway and pathogen covered in this study.

It is important to recall, however, that the pathogen risk estimated in this study refers to a model WWTS (i.e., primary, secondary and tertiary wastewater treatment, anaerobic sludge digestion, and land application of sewage sludge). In particular, this study was entirely based 
on pathogen concentrations and a set of exposure pathways described in the literature rather than the actual pathogen concentrations and exposure pathways characteristic of a specific site. The inclusion of pathogen risk in a site-specific LCA study through QMRA would presumably benefit from site-specific data on pathogen levels as well as actual transport, fate and exposure pathways and conditions applying to the specific plant rather than a model scenario. A site-specific study would furthermore rely solely on a model-based approach (for site-specific pathogen levels as well as fate and exposure pathways and conditions), and a literature-based approach would not be necessary. Yet the question remains whether QMRA models could be adapted in such a way that they require less site-specific data and hence produce risk estimates more akin to the risk estimates for other impacts on human health as modeled in LCIA with less site-specificity and less exposure pathways. Whether these issues and questions need to be addressed also depends on whether the inclusion of pathogen risk in LCA appears to be important, that is, if it can make up a significant share of the total potential impact on human health in wastewater and sludge management systems. Such a comparison is reported and discussed in part 2 of this article series ${ }^{29}$.

\section{ACKNOWLEDGMENTS}

This project has received funding from the European Union's Seventh Programme for research, technological development and demonstration under grant agreement No 265156 ROUTES. This research at the same time served as a pre-study for further research funded by the Swedish Research Council for Environment, Agricultural Sciences and Spatial Planning (FORMAS) under grant agreement No. 2012-1122.

\section{FIGURES}

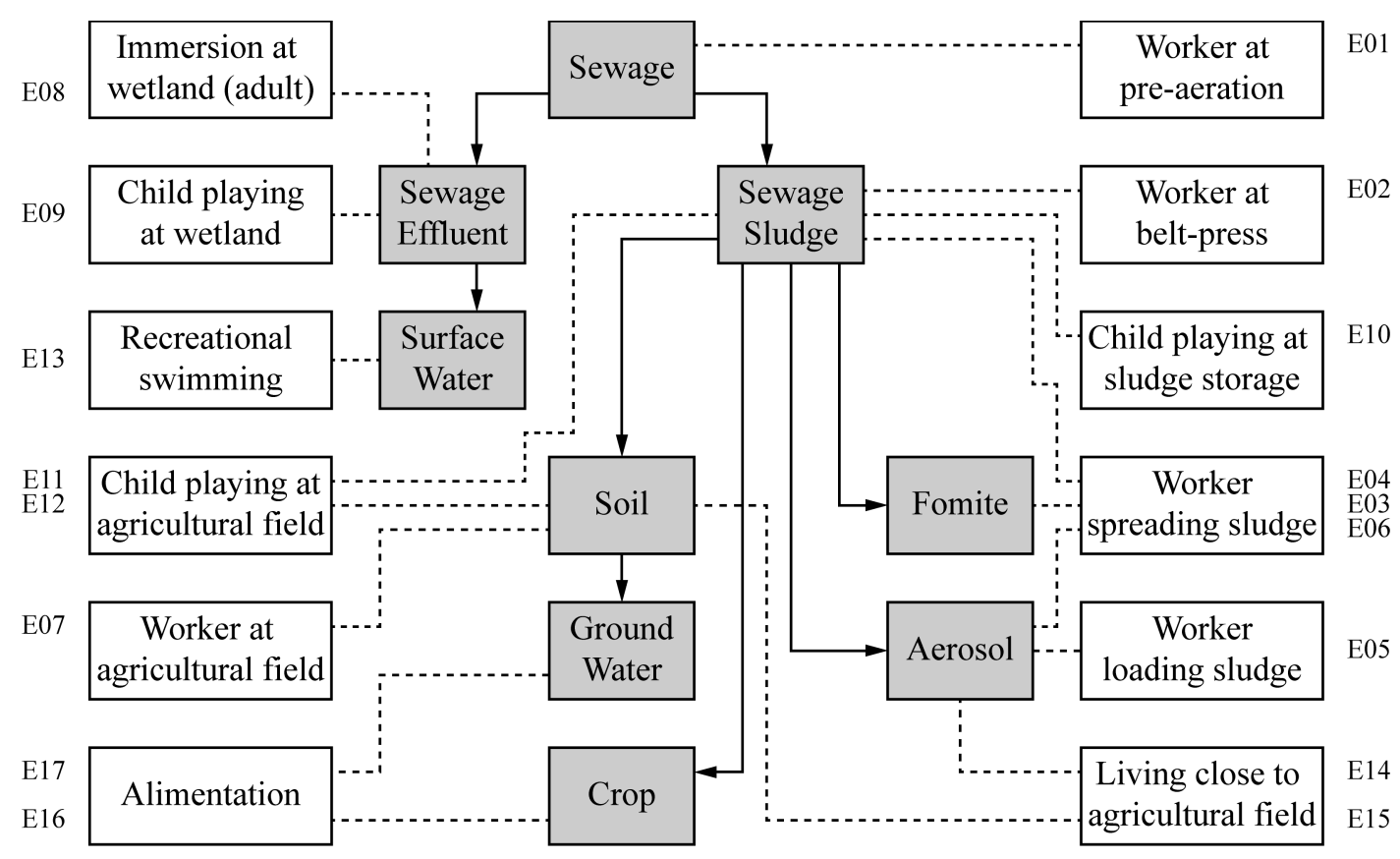


Figure 1. Transport and exposure pathways considered for the estimation of pathogen risk. Solid arrows represent transport pathways, dashed lines represent exposure pathways. Grey boxes represent environmental compartments. White boxes represent exposure events and the numbers besides the white boxes represent exposure pathway IDs as defined in Table 1.

P01 P02 P03 P04 P05 P06 P07 P08 P09 P10

\begin{tabular}{|c|c|c|c|c|c|c|c|c|c|c|}
\hline E01 & $\mathrm{m}$ & $\mathrm{m}$ & $\mathrm{m}$ & $\mathrm{m}$ & $\mathrm{m}$ & $\mathrm{m}$ & & & $\mathrm{m}$ & $\mathrm{m}$ \\
\hline E02 & $\mathrm{m}$ & & $\mathrm{m}$ & & $\mathrm{m}$ & $\mathrm{m}$ & $\mathrm{m}$ & $\mathrm{m}$ & $\mathrm{m}$ & $\mathrm{m}$ \\
\hline E03 & $\mathrm{m}$ & & $\mathrm{m}$ & & $\mathrm{m}$ & & $\mathrm{m}$ & & $\mathrm{m}$ & $\mathrm{m}$ \\
\hline E04 & $\mathrm{m}$ & & $\mathrm{m}$ & & $\mathrm{m}$ & & $\mathrm{m}$ & & $\mathrm{m}$ & $\mathrm{m}$ \\
\hline E05 & $\mathrm{m}$ & & $\mathrm{m}$ & & $\mathrm{m}$ & & $\mathrm{m}$ & & & \\
\hline E06 & $\mathrm{m}$ & & $\mathrm{m}$ & & $\mathrm{m}$ & & $\mathrm{m}$ & & & \\
\hline E07 & $\mathrm{m}$ & & $\mathrm{m}$ & & $\mathrm{m}$ & & $\mathrm{m}$ & & $\mathrm{m}$ & $\mathrm{m}$ \\
\hline E08 & $\mathrm{m}$ & $\mathrm{m}$ & $\mathrm{m}$ & $\mathrm{m}$ & $\mathrm{m}$ & $\mathrm{m}$ & $\mathrm{m}$ & & $\mathrm{m}$ & $\mathrm{m}$ \\
\hline E09 & $\mathrm{m}$ & $\mathrm{m}$ & $\mathrm{m}$ & $\mathrm{m}$ & $\mathrm{m}$ & $\mathrm{m}$ & $\mathrm{m}$ & & $\mathrm{m}$ & $\mathrm{m}$ \\
\hline E10 & $\mathrm{m}$ & & $\mathrm{m}$ & & $\mathrm{m}$ & & $\mathrm{m}$ & & $\mathrm{m}$ & $\mathrm{m}$ \\
\hline E11 & $\mathrm{m}$ & & $\mathrm{m}$ & & $\mathrm{m}$ & & $\mathrm{m}$ & & $\mathrm{m}$ & $\mathrm{m}$ \\
\hline E12 & $\mathrm{m}$ & & $\mathrm{m}$ & & $\mathrm{m}$ & & $\mathrm{m}$ & & $\mathrm{m}$ & $\mathrm{m}$ \\
\hline E13 & & & & & & & & & & \\
\hline E14 & $\mathrm{m}$ & & $\mathrm{m}$ & & $\mathrm{m}$ & & $\mathrm{m}$ & & & \\
\hline E15 & $\mathrm{m}$ & & $\mathrm{m}$ & & $\mathrm{m}$ & & $\mathrm{m}$ & & $\mathrm{m}$ & $\mathrm{m}$ \\
\hline E16 & $\mathrm{m}$ & & $\mathrm{m}$ & & $\mathrm{m}$ & & $\mathrm{m}$ & & $\mathrm{m}$ & $\mathrm{m}$ \\
\hline E17 & & & & & & & & & & \\
\hline
\end{tabular}

Figure 2. Combinations of pathogen and exposure pathway covered in the literature-based approach (grey boxes) and the model-based approach (boxes marked with 'm'). Note that for pathogen P03 (Enterovirus) no severity factor for the conversion of probabilities or cases of infection or illness into a burden of disease (in DALY) were available, hence Enterovirus was not included in the overall pathogen risk estimate.

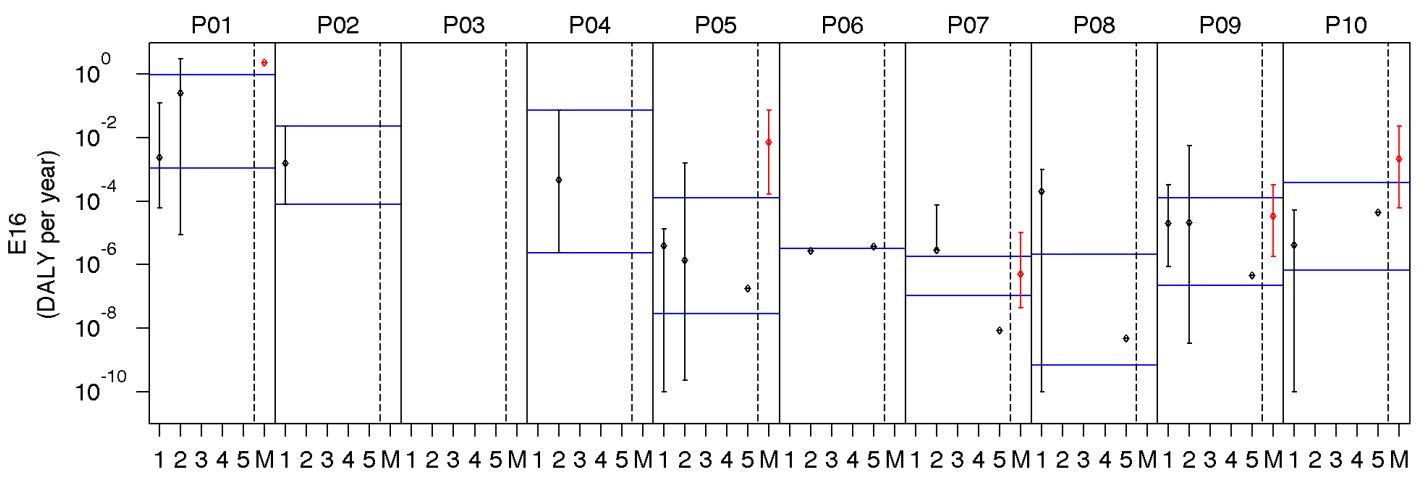

Figure 3. Burden of disease estimates for exposure pathway E16. Black ranges (left of the vertical dashed line for each respective pathogen) represent literature-based estimates for five different previous QMRA studies (thus, in theory, up to five literature-based ranges from left to right). Red ranges (right of the vertical dashed line for each respective pathogen) represent the model-based estimate. Black and red diamonds represent mean values. Error bars are a result of the ranges provided in the previous QMRA studies (literature-based approach) and parameter uncertainty (model-based approach), and in most cases represent $5 \%$ and $95 \%$ percentiles. Blue (horizontal) lines represent low 
This is a peer reviewed manuscript accepted for publication in Environmental Science and Technology. The final version of this manuscript is available at http://dx.doi.org/10.1021/es501480q.

and high estimates of the triangulation. The respective graphs for all other exposure pathways are provided in the Supporting Information. 


\section{TABLES}

Table 1. Overview of exposure pathways considered in this study including exposure frequency and individuals exposed.

\begin{tabular}{|c|c|c|c|c|c|c|c|}
\hline ID & Specific activity & Exposure & & $\mathrm{FE}$ & IE & MOD & LIT \\
\hline E01 & Worker at pre-aeration & Raw sewage & Ingestion & 52 & 2 & [19] & [19] \\
\hline E02 & Worker at belt-press & Raw sludge & Ingestion & 208 & 1 & [19] & [19] \\
\hline E03 & Worker spreading sludge & Fomite & Fomite contact & 30 & 2 & {$[14,19]$} & [14] \\
\hline E04 & Worker spreading sludge & Treated sludge & Ingestion & 30 & 2 & [19] & {$[14,16]$} \\
\hline E05 & Worker loading sludge & Aerosol & Inhalation & 30 & 2 & [14] & [18] \\
\hline E06 & Worker spreading sludge & Aerosol & Inhalation & 30 & 2 & [14] & {$[14,16,18]$} \\
\hline E07 & Worker at agricultural field & Soil & Ingestion & 52 & 30 & [14] & {$[14,19]$} \\
\hline E08 & Immersion at wetland inlet & Effluent & Ingestion & 1 & 2 & [19] & [19] \\
\hline E09 & Child playing at wetland inlet & Effluent & Ingestion & 2 & 30 & [19] & [19] \\
\hline E10 & Child playing at sludge storage & Treated sludge & Ingestion & 1 & 2 & [19] & [19] \\
\hline E11 & Child playing on field & Treated sludge & Ingestion & 1 & 2 & {$[14,19]$} & [16] \\
\hline E12 & Child playing on field & Soil & Ingestion & 2 & 30 & {$[14,19]$} & [14] \\
\hline E13 & Recreational swimming & Surface water & Ingestion & 10 & 300 & & [19] \\
\hline E14 & Living close to field & Aerosol & Inhalation & 2 & 300 & [14] & {$[14,16]$} \\
\hline E15 & Living close to field & Soil & Ingestion & 2 & 300 & [14] & [14] \\
\hline E16 & Alimentation & Crops & Ingestion & 2 & 500 & [14] & {$[14,17,19]$} \\
\hline E17 & Alimentation & Drinking water & Ingestion & 2 & 500 & & {$[16]$} \\
\hline
\end{tabular}

$\mathrm{FE}=$ frequency of exposure (based on Westrell and colleagues ${ }^{14}$ ); IE = number of individual exposed (based on Westrell and colleagues ${ }^{14}$ ); MOD $=$ references underlying the model-based approach; LIT = references underlying the literature-based approach

Table 2. Overview of considered pathogen groups and model organisms.

\begin{tabular}{lll}
\hline ID & Pathogen group & Model organism \\
\hline P01 & Mastadenovirus & Adenovirus \\
P02 & Rotavirus & Rotavirus \\
P03 & Enterovirus & Coxsackievirus \\
P04 & Norovirus & Norovirus \\
P05 & Salmonella & Non-typhi salmonella \\
P06 & Campylobacter & C. jejuni \\
P07 & Listeria & L. monocytogenes \\
P08 & Escherichia & E. coli O157:H7 \\
P09 & Cryptosporidium & C. parvum \\
P10 & Giardia & G. lamblia \\
\hline
\end{tabular}

Table 3. Overall burden of disease estimates for the literature-based approach (five distinct previous QMRA studies), the model-based approach, and the combination of the two approaches.

\begin{tabular}{llllllll}
\hline Approach & Reference & $\mathrm{P} \S$ & $\mathrm{E} \S$ & $\mathrm{P} * \mathrm{E} \S$ & Low $^{\circ}$ & High $^{\circ}$ & $\mathrm{Mean}^{\circ}$ \\
\hline Literature-based & 19 & $6(6)$ & 9 & 54 & 0.1 & 0.7 & 0.2 \\
Literature-based & 14 & $7(6)$ & 7 & 42 & 0.008 & 3.4 & 0.3 \\
Literature-based & 16 & $1(1)$ & 5 & 5 & 0.002 & 0.2 & 0.0 \\
Literature-based & 18 & $2(1)$ & 2 & 2 & $<0.001$ & $<0.001$ & $<0.001$ \\
Literature-based & 17 & $7(6)$ & 1 & 6 & $<0.001$ & $<0.001$ & $<0.001$ \\
Model-based & This study & $10(9)$ & 15 & 82 & 5.7 & 7.3 & 6.1 \\
Combination & This study & $10(9)$ & 17 & 120 & 0.2 & 8.6 & --- \\
\hline
\end{tabular}

$\S \mathrm{P}=$ number of pathogens covered in the respective study, numbers in parentheses refer to the number of pathogens where severity factors are available; $\mathrm{E}=$ number of exposure pathways covered in the respective study; $\mathrm{P} * \mathrm{E}=$ number of combinations of pathogens and exposure pathogens covered in the respective study.

${ }^{\circ}$ Low and high values are a result of the ranges provided in the previous QMRA studies (literature-based approach) and parameter uncertainty (model-based approach), and in most cases represent $5 \%$ and $95 \%$ percentiles. 


\section{ASSOCIATED CONTENT}

Supporting Information Available. Details on previous QMRA studies forming the basis of this study as well as on transport and fate, exposure, dose-response, and risk characterization models used in this study. Detailed results for every combination of pathogen and exposure pathway considered in this study. This information is available free of charge via the Internet at http://pubs.acs.org/ .

\section{REFERENCES}

(1) Cooper, J.; Lombardi, R.; Boardman, D.; Carliell-Marquet, C. The future distribution and production of global phosphate rock reserves. Resour. Conserv. Recy. 2011, 57, 7886.

(2) Lougheed, T. Phosphorus paradox - scarcity and overabundance of a key nutrient. Environ. Health Persp. 2011, 119(5), A208-A213.

(3) Neset, T.S.; Cordell, D. Global phosphorus scarcity: Identifying synergies for a sustainable future. J. Sci. Food Agr. 2012, 92, 2-6.

(4) O’Connor, G.A.; Elliott, H.A.; Basta, N.T.; Bastian, R.K.; Pierzynski, G.M.; Sims, R.C.; Smith, J.E. Sustainable land application: An overview. J. Environ. Qual. 2005, 34(1), 7-17.

(5) Rhind, S.M.; Kyle, C.E.; Ruffie, H.; Calmettes, E.; Osprey, M.; Zhang, Z.L.; Hamilton, D.; McKenzie, C. Short- and long- term temporal changes in soil concentrations of selected endocrine disrupting compounds (EDCs) following single or multiple applications of sewage sludge to pastures. Environ. Pollut. 2013, 181, 262-270.

(6) Viau, E.; Bibby, K.; Paez-Rubio, T.; Peccia, J. Toward a consensus view on the infectious risks associated with land application of sewage sludge. Environ. Sci. Technol. 2011, 45, 5459-5469.

(7) Smith S.R. Organic contaminants in sewage sludge (biosolids) and their significance for agricultural recycling. Philos. T. R. Soc. A 2009, 367, 4005-4041.

(8) Svanström, M.; Bertanza, G.; Bolzonella, D.; Canato, M.; Collivignarelli, C.; Heimersson, S.; Laera, G.; Mininni, G.; Peters, G.; Tomei, M.C. Method for technical, economic and environmental assessment of advanced sludge processing routes. Water Sci. Technol. 2014, accepted manuscript.

(9) Yoshida, H.; Christensen, T.H.; Scheutz, C. Life cycle assessment of sewage sludge management: A review. Waste Manage. Res. 2013, 31(11), 1083-1101.

(10) Corominas, L.; Foley, J.; Guest, J.S.; Hospido, A.; Larsen, H.F.; Morera, S.; Shaw, A. Life cycle assessment applied to wastewater treatment: State of the art. Water Res. 2013, 47, 5480-5492.

(11) Brooks, J.P.; Josephson, K.L.; Gerba, C.P.; Haas, C.N.; Pepper, I.L. A national study on the residential impact of biological aerosols from the land application of biosolids. $J$. Appl. Microbiol. 2005, 99, 310-322.

(12) Brooks, J.P.; Tanner, B.D.; Gerba, C.P.; Haas, C.N.; Pepper, I.L. Estimation of bioaerosol risk of infection to residents adjacent to a land applied biosolids site using an empirically derived transport model. J. Appl. Microbiol. 2005, 98, 397-405. 
(13) Brooks, J.P.; Gerba, C.P.; Pepper, I.L. Comparative microbial risks of land applied biosolids and animal manure. Proceedings of Residuals and Biosolids 2009, 161-173.

(14) Brooks, J.P.; McLaughlin, M.R.; Gerba, C.P.; Pepper, I.L. Land application of manure and class B biosolids: An occupational and public quantitative microbial risk assessment. J. Environ. Qual. 2012, 41, 2009- 2023.

(15) Eisenberg, J.N.S.; Soller, J.A.; Scott, J.; Eisenberg, D.M.; Colford, J.M. A dynamic model to assess microbial health risks associated with beneficial uses of biosolids. Risk Anal. 2004, 24(1), 221-235.

(16) Eisenberg, J.N.S.; Moore, K.; Soller, J.A.; Eisenberg, D.; Colford, M. Microbial risk assessment framework for exposure to amended sludge projects. Environ. Health Persp. 2008, 116(6), 727-733.

(17) Gale, P. Land application of treated sewage sludge: Quantifying pathogen risks from consumption of crops. J. Appl. Microbiol. 2005, 98, 380-396.

(18) Tanner, B.D.; Brooks, J.P.; Gerba, C.P.; Haas, C.N.; Josephson, K.L.; Pepper, I.L. Estimated occupational risk from bioaerosols generated during land application of class B biosolids. J. Environ. Qual. 2008, 37, 2311-2321.

(19) Westrell, T.; Schönning, C.; Stenström, T.A.; Ashbolt, N.J. QMRA (quantitative microbial risk assessment) and HACCP (hazard analysis and critical control points) for management of pathogens in wastewater and sewage sludge treatment and reuse. Water Sci. Technol. 2004, 50(2), 23-30.

(20) Murray, C.; Lopez, A. Global burden of disease: A comprehensive assessment of mortality and disability from diseases, injuries, and risk factors in 1990 and projected to 2020. Global burden of disease and injury series, Volume 1. Harvard School of Public Health, World Bank, World Health Organisation, 1996.

(21) Ayuso-Gabella, N.; Page, D.; Masciopinto, C.; Aharoni, A.; Salgot M.; Wintgens, T. Quantifying the effect of managed aquifer recharge on the microbiological human health risks of irrigating crops with recycled water. Agr. Water Manage. 2011, 99, 93102.

(22) Barker, S.; O’Toole, J.; Sinclair, M.I.; Leder, K.; Malawaraarachchi, M.; Hamilton, A.J. A probabilistic model of Norovirus burden of disease associated with greywater irrigation of home-produced lettuce in Melbourne, Australia. Water Res. 2013, 47, 1421-1432.

(23) Barker, S.F.; Packer, M.; Scales, P.J.; Gray, S.; Snape, I.; Hamilton, A.J. Pathogen reduction requirements for direct potable reuse in Antarctica: Evaluating human health risks in small communities. Sci. Total Environ. 2013, 461-462, 723-733.

(24) Chen, Z.; Ngo, H.H.; Guo, W. A critical review on sustainability assessment of recycled water schemes. Sci. Total Environ. 2012, 426, 13-31.

(25) Forslund, A.; Ensink, J.H.J.; Battilani, A.; Kljujev, I.; Gola, S.; Raicevic, V.; Jovanovic, Z.; Stikic, R.; Sandei, L.; Fletcher, T.; Dalsgaard, A. Faecal contamination and hygiene aspect associated with the use of treated wastewater and canal water for irrigation of potatoes (solanum tuberosum). Agr. Water Manage. 2010, 98, 440-450. 
(26) Hamilton, A.J.; Stagnitti, F.; Kumarage, S.C.; Premier, R.R. RIRA: A tool for conducting health risk assessments for irrigation of edible crops with recycled water. Comput. Electron. Agr. 2007, 57, 80-87.

(27) Roser, D.J.; Khan, S.; Davies, C.; Signor, R.S.; Petterson, S.R.; Ashbolt, N.J. Operational application of quantitative microbial risk assessment in the field of water reuse. Proceedings of the 3rd AWA Water Reuse and Recycling Conference (REUSE07) 2007.

(28) Aramaki, T.; Galal, M.; Hanaki, K. Estimation of reduced and increasing health risks by installation of urban wastewater systems. Water Sci. Technol. 2006, 53(9), 247-252.

(29) Heimersson, S.; Harder, R.; Peters, G.M.; Svanström, M. Including pathogen risk in life cycle assessment of wastewater management - Part 2: Quantitative comparison of pathogen risk to other impacts on human health. 2014, submitted manuscript.

(30) Gaunt, E.R.; Harvala, H.; McIntyre, C.; Templeton, K.E.; Simmonds P. Burden of disease of the most commonly detected respiratory viruses in hospitalized patients calculated using the disability adjusted life year (DALY) model. J. Clin. Virol. 2011, 52, 215-221.

(31) Havelaar, A.H.; Friesema, I.H.M.; van Pelt, W. Burden of disease of food-related pathogens in the Netherlands, 2012. National Institute for Public Health and the Environment: Bilthoven, the Netherlands, 2012.

(32) Havelaar, A.H.; Melse, J.M. Quantifying public health risk in the WHO guidelines for drinking-water quality. National Institute for Public Health and the Environment: Bilthoven, the Netherlands, 2003.

(33) Venglovsky, J.; Martinez, J.; Placha, I. Hygienic and ecological risks connected with utilization of animal manures and biosolids in agriculture. Livest. Sci. 2006, 102(3), 197-203.

(34) Wéry, N.; Lhoutellier, C.; Ducray, F.; Delgenès, J.-P.; Godon, J.-J. Behaviour of pathogenic and indicator bacteria during urban wastewater treatment and sludge composting, as revealed by quantitative PCR. Water Res. 2008, 42, 53-62.

(35) Campos, C.J.A.; Avant, G.; Lowther, J.; Till, D.; Lees, D. Levels of Norovirus and E. coli in untreated, biologically treated and UV-disinfected sewage effluent discharged to a shellfish water. J. Water Resour. Prot. 2013, 5, 978-982.

(36) Carducci, A.; Morici, P.; Pizzi, F.; Battistini, R.; Rovini, E.; Verani, M. Study of the viral removal efficiency in a urban wastewater treatment plant. Water Sci. Technol. 2008, 58(4), 893-897.

(37) Chauret, C.; Springthorpe, S.; Sattar, S. Fate of cryptosporidium oocysts, giardia cysts, and microbial indicators during wastewater treatment and anaerobic sludge digestion. Can. J. Microbiol. 1999, 45(3), 257-262.

(38) Costán-Longares, A.; Montemayor, M.; Payán, A.; Méndez, J.; Jofre, J.; Mujeriego, R.; Lucena, F. Microbial indicators and pathogens: Removal, relationships and predictive capabilities in water reclamation facilities. Water Res. 2008, 42(17), 4439-4448.

(39) Flannery, J.; Keaveney, S.; Rajko-Nenow, P.; O’Flaherty, V.; Doré, W. Concentration of norovirus during wastewater treatment and its impact on oyster contamination. Appl. Environ. Microb. 2012, 78(9), 3400-3406. 
(40) Garrec, N.; Picard-Bonnaud, F.; Pourcher, A.M. Occurrence of Listeria sp. and L. monocytogenes in sewage sludge used for land application: Effect of dewatering, liming and storage in tank on survival of Listeria species. FEMS Immunol. Med. Mic. 2003, 35 , $275-283$.

(41) Guzmán, C.; Jofre, J.; Montemayor, M.; Lucena, F. Occurrence and levels of indicators and selected pathogens in different sludges and biosolids. J. Appl. Microbiol. 2007, 103, 2420-2429.

(42) Hachich, E.M.; Galvani, A.T.; Padula, J.A.; Stoppe, N.C.; Garcia, S.C.; Bonanno, V.M.S.; Barbosa, M.R.F.; Sato, M.I.Z. Pathogenic parasites and enteroviruses in wastewater: Support for a regulation on water reuse. Water Sci. Technol. 2013, 67(7), $1512-1518$.

(43) Hokajärvi, A.M.; Pitkänen, T.; Siljanen, H.P.M.; Nakari, U.M.; Torvinen, E.; Siitonen, A.; Miettinen, I.T. Occurrence of thermotolerant Campylobacter spp. and adenoviruses in Finnish bathing waters and purified sewage effluents. J. Water Health 2013, 11(1), 120-134.

(44) Jiménez-Cisneros, B.E.; Maya-Rendón, C.; Salgado-Velásquez, G. The elimination of helminth ova, faecal coli- forms, salmonella and protozoan cysts by various physicochemical processes in wastewater and sludge. Water Sci. Technol. 2001, 43(12), 179-182.

(45) Jones, K. Campylobacters in water, sewage and the environment. J. Appl. Microbiol. 2001, 90, 68S-79S.

(46) Koenraad, P.M.F.J.; Hazeleger, W.C.; van der Laan, T.; Beumer, R.R.; Rombouts, F.M. Survey of Campylobacter spp. in sewage plants in The Netherlands. Food Microbiol. 1994, 11, 65-73.

(47) Lalancette, C.; Généreux, M.; Mailly, J.; Servais, P.; Côté, C.; Michaud, A.; Di Giovanni, GD.; Prévost, M. Total and infectious Cryptosporidium oocyst and total Giardia cyst concentrations from distinct agricultural and urban contamination sources in Eastern Canada. J. Water Health 2012, 10(1), 147-160.

(48) Li, D.; Gu, A.; Zeng, S.Y.; Yang, W.; He, M.; Shi, H.C. Monitoring and evaluation of infectious rotaviruses in various wastewater effluents and receiving waters revealed correlation and seasonal pattern of occurrences. J. Appl. Microbiol. 2011, 110, 11291137.

(49) Montemayor, M.; Valero, F.; Jofre, J.; Lucena, F. Occurrence of Cryptosporidium spp. oocysts in raw and treated sewage and river water in north-eastern Spain. J. Appl. Microbiol. 2005, 99, 1455-1462.

(50) Nordgren, J.; Matussek, A.; Mattson, A.; Svensson, L.; Lindgren, P.E. Prevalence of norovirus and factors influencing virus concentrations during one year in a full-scale wastewater treatment plant. Water Res. 2009, 43, 1117-1125.

(51) Paillard, D.; Dubois, V.; Thiebaut, R.; Nathier, F.; Hoogland, E.; Caumette, P.; Quentin, C. Occurrence of Listeria spp. in effluents of French urban wastewater treatment plants. Appl. Environ. Microb. 2005, 71(11), 7562-7566.

(52) Sedmak, G.; Bina, D.; MacDonald, J. Assessment of an enterovirus sewage surveillance system by comparison of clinical isolates with sewage isolates from Milwaukee, 
Wisconsin, collected August 1994 to December 2002. Appl. Environ. Microb. 2003, 69(12), 7181-7187.

(53) Sidhu, J.P.; Toze, S.G. Human pathogens and their indicators in biosolids: A literature review. Environ. Int. 2009, 35(1), 187-201.

(54) Couch, R.B.; Gerone, P.; Fleet, W.; Lang, D.; Griffith, W.; Knight, W. Production of illness with a small-particle aerosol of coxsackie A21. J. Clin. Invest. 1965, 44, 535542.

(55) Crockett, C.S.; Haas, C.N.; Fazil, A.M.; Rose, J.B.; Gerba, C.P. Prevalence of shigellosis in the U.S.: Consistency with dose-response information. Int. J. Food Microbiol. 1996, 30, 87-99.

(56) Haas, C.N.; Crockett, C.S.; Rose, J.B.; Gerba, C.P.; Fazil, A.M. Assessing the risk posed by oocysts in drinking water. J. Am. Water Works Ass. 1996, 88, 131- 136.

(57) Haas, C.N.; Gerba, C.P.; Regli, S. Risk assessment of virus in drinking water. Risk Anal. 1993, 13, 545-552.

(58) Haas, C.N.; Rose, J.B.; Gerba, C.P. Quantitative microbial risk assessment. John Wiley and Sons, Inc: New York, NY, 1999.

(59) Rose, J.B.; Gerba, C.P.; Jakubowski, W. Survey of potable water supplies for cryptosporidium and giardia. Environ. Sci. Technol. 1991, 25, 1393-1400.

(60) Teunis, P.F.M.; Moe, C.L.; Liu, P.; Miller, S.E.; Lindesmith, L.; Baric, R.S.; Le Pendu, J.; Calderon, R.L. Norwalk virus: How infectious is it? J. Med. Virol. 2008, 80, 14681476.

(61) Teunis, P.F.M.; Nagelkerke, N.J.D.; Haas, C.N. Dose response models for infectious gastroenteritis. Risk Anal. 1999, 19, 1251-1259.

(62) Teunis, P.F.M.; van der Heijden, O.G.; van der Giessen, J.W.B.; Havelaar, A.H. The dose-response relation in human volunteers for gastro-intestinal pathogens. National Institute for Public Health and the Environment: Bilthoven, the Netherlands, 1996.

(63) Altenburger, R.; Backhaus, T.; Boedeker, W.; Faust, M.; Scholze, M. Simplifying complexity: Mixture toxicity assessment in the last 20 years. Environ. Toxicol. Chem. 2013, 32(8), 1685-1687.

(64) Sexton, K. Cumulative risk assessment: An overview of methodological approaches for evaluating combined health effects from exposure to multiple environmental stressors. Int. J. Environ. Res. Public Health 2012, 9:370-390.

(65) Larsen, H.F.; Olsen, S.I.; Hauschild, M.; Laurent, A. NEPTUNE, New sustainable concepts and processes for optimization and upgrading municipal wastewater and sludge treatment, Work Package 4 - Assessment of environmental sustainability and best practice, Deliverable 4.2 - Methodology for including specific biological effects and pathogen aspects into LCA. Technical University of Denmark: Lyngby, Denmark, 2009. 